\title{
An Investigation of the Significant Criteria of Vegetation Selection and Planting Arrangement in Designing Urban Nodes
}

\author{
Mastura Adam*, Norafida Ab Ghafar and Taofeekat Mustapha \\ Department of Architecture, Faculty of Built Environment, University of Malaya, 50603 Kuala \\ Lumpur, Malaysia. \\ *mastura@um.edu.my
}

Unresponsive design guidelines for open spaces and the continuous allocation of land for the construction of buildings has led to the 'concretisation' of urbanscapes. This has resulted in the urban heat island effect marking the increase in air temperature making urban spaces almost unbearable for urban residents to dwell in. However, new effort is being made to reduce the effect of heat gain at the pedestrian level by planting vegetation in open spaces particularly urban nodes to create a comfortable outdoor environment. Appropriate vegetation selection in landscape design which is capable of reducing outdoor air temperature, is needed in designing urban nodes in hot-humid climates. The study is aimed to investigate the effectiveness of different vegetation types and their planting arrangement in adequately shading outdoor spaces for pedestrian activities. Two node intersections in Kuala Lumpur's urban space were selected based on vegetation type and planting arrangement. Daylight intensity was measured using the lux meters and the shadow casted underneath the vegetation. Human activity within the area was also observed to determine which vegetation type and planting arrangement is most suitable for pedestrian activity. Results revealed that the vegetation types and its planting arrangements significantly influences the amount of daylight penetrating the tree foliage and shadow casted on the ground which encourages human interaction at the node intersections.

Keywords: Daylight Intensity, Vegetation Selection, Planting Arrangement, Shadow Casting, Urban Nodes.

\section{INTRODUCTION}

Hot-humid regions are characterised as nonarid climates taking up much of the equatorial belt where day length and temperature remain relatively constant throughout the year. However, developing tropical cities are experiencing microclimatic variations due to rapid urban growth with much reference to the evolving urban environment. This predisposition has increased demand on the comfort requirements in the design of outdoor urban spaces. As comfort at street level in the urban environment deteriorates, urban dwellers are losing their ability to create meaningful relationships with their urban environment and spending longer time indoors in controlled air temperature (Ahmed, 2003).

Asian cities such as Kuala Lumpur (KL) are experiencing unprecedented urbanization that has progressively modified urban spaces, building structures and human activities
(Ahmed, 2003) causing rapid warming in cities seen in recent times ( $\mathrm{Hu}$ and Brunsell, 2015; Stocker et at., 2013; Mayer et al., 2008). Green allocated spaces in the city centre continue to disappear due to vast development of high rise buildings. These high-rises are creating rougher urbanscapes, less windy and often drier environment as compare to their rural counterparts resulting in higher temperatures in the city. Hence, heat waves have become more frequent, more intense and longer lasting (Meehl and Tebaldi 2004; Thorsson, 2010). With the growing urban population, a threat to human health and well-being is posed due to this increased temperature and air pollution in urban environments (Myers and Patz, 2009 and Patz et al., 2005). Lindberg (2011) suggested the use of appropriate vegetation foliage and a suitable planting arrangement in city spaces as a means to provide shade which significantly reduces the outdoor temperature and increases 
overall comfort in pedestrian zones. In the context of KL, the microclimate has contributed to the public's unwillingness to walk on city streets. The heat condition and constant exposure to the sun could reach alarming levels, where over exposure and physical activity could lead to heatstroke, sunstrokes, muscles cramps, heat exhaustion, severe heat rash and pulmonary disorder (Kleerekoper et al., 2012). To compound to the high air temperature and humidity levels, greater demands are placed annually on the use of mechanical cooling systems in private residents, offices and commercial areas. Car traffic activities in the city centre further contribute to increasing the air temperature of the outdoor environment particularly at street level (Kleerekoper et al., 2012). It can also be said that heat gain has contributed to the immense pressure on private vehicles as a preferred mode of transportation within the city. These are the contributing factors to the urban heat island phenomenon in KL. The temperature in the city centre is the highest due to high density, high rise developments and ground surfaces covered with black tarmac, blocks of marble, granite or tiles which are heat absorbents when exposed to direct sunlight (Elsayed, 2012a). Eliasson (1993), Shashua-Bar and Hoffman (2000) and Elsayed (2009) in their studies confirmed that large green areas have positive effects on the temperature in the city. In order to mitigate the effects of urban heat island in the city, Elsayed (2012a) suggested that well planned tree planting programs should be reinforced in the city of KL as a main strategy to ameliorate the excess heat.

This study investigates the vegetation type and planting arrangement and their performance in reducing daylight intensity and shadow casting ability on open surfaces in KL. In this study, two nodes intersections in KL's urban space were selected and compared in terms of their effectiveness in contributing to a comfortable pedestrian environment. This study is divided into three objectives: i) to identify the vegetation selection and its planting arrangement in the selected urban node intersections, ii) to investigate the effectiveness of the vegetation selection and its planting arrangement in relation to daylight penetration on the ground surface, and iii) to analyse the amount of daylight penetrating the ground surface influencing the human activities at the nodes intersections.

\section{VEGETATION SELECTIONS AND PLANTING ARRANGEMENT}

The effect of vegetation on the microclimate, landscape character, temperature control and energy consumption has been measured and evaluated prolifically in literature by Mcpherson (2001), Streiling and Matzarakis (2003), Picot (2004), Shahidan et al. (2010). These studies uncovered that the physical characteristics of a tree are primary factor considered in regulating microclimatic conditions for thermal comfort (Shahidan et al., 2010).

Trees have a multitude of functional, psychological, ecology and aesthetic advantages to the city and its occupants. The tree's canopy is a major component contributing to the microclimatic environment (Shahidan et al., 2010). Shade from a tree's canopy is associated with the vegetation foliage arrangement that significantly influences microclimate factors such as light intensity, wind velocity, solar radiation (Shahidan et al., 2010) and the filtering dust and noise (Lindberg, 2011). The structure of the tree canopy such as its form, height, branching structure, foliage density and leaf cover is vital to the degree of shade created (Kenny et al., 2009a, b; Brown, 2011; Shahidan et al., 2010).

Foliage geometry of tree canopies create shade that can reduce diffused light and glare from the sky and surrounding areas - that fall on the ground under the tree, thereby altering the heat exchange between the space below (Shahidan et al., 2010). This is done with the tree's crown consisting of branches, leaves and twigs, providing shade and reducing wind speed (Kenny et al., 2009a, b; Brown, 2011; Shahidan et al., 2010). This has an impact on the comfort of people walking or sitting under the shade (Shahidan et al., 2010). During the day, shading trees also indirectly reduce heat gain by altering terrestrial radiation and ultimately reducing ground surface 
temperatures (Akbari et al., 2001; Shahidan et al., 2010).

The ability of shading trees to improve comfort levels by intercepting and storing heat from direct solar gains in outdoor spaces leads to a significant reduction in downward energy flow in the form of visible light and solar infrared waves (Kenny et al., 2009a, b; Brown, 2011; Shahidan et al., 2010). According to Brown, (2011) and Shahidan et al. (2010), all trees can filter between $80 \%$ to $90 \%$ of the incoming radiation depending on their leaf density and planting arrangement (of the leaves of the tree and of the trees in the space).
Furthermore, about $20 \%$ of the infrared is absorbed, $50 \%$ is reflected and only $30 \%$ is transmitted. Cumulatively, a total of approximately $50 \%$ of visible and infrared radiation are absorbed, $30 \%$ is reflected and only $20 \%$ is transmitted (refer Figure 1). The more layers of leaves added, the better the efficiency at decreasing solar radiation under the tree canopy by shading (Shahidan et al., 2010). Therefore, the denser the tree foliage and the closer the trees are to each other, the lesser the amount of visible and infrared radiation falling on the ground underneath the tree canopy.

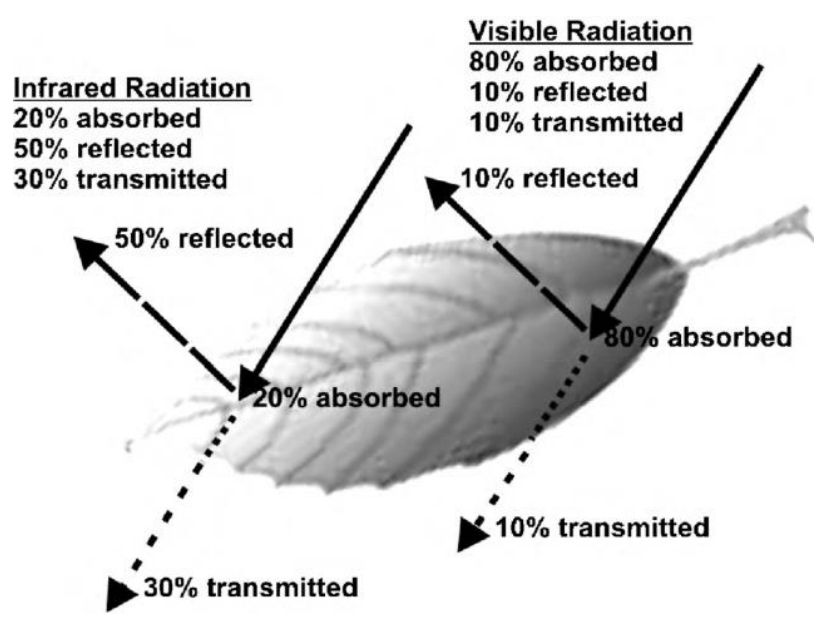

Figure 1: Leaf absorption, transmission and reflection modified from Shahidan et al., 2010).

A tree's shading performance differs with each species and their radiation filtration effectiveness will influence microclimate modification (Shahidan et al., 2010). This makes it necessary to investigate different species shading capacity and their planting arrangement to understand the impact of each vegetation type on outdoor comfort levels for pedestrian activity. This paper does not directly measure the infrared radiation under the tree but uses the light intensity to measure the shading provided by the vegetation. The research uses the theory presented by Kenny et al. (2009a, b), Brown (2011) and Shahidan et al. (2010) to investigate the amount of daylight penetrating the tree foliage and the shadow casted on the ground to measure the shading capacity of different tree types.
Nodes are described as strategic points where people enter and exit the city. The nodes are typically the intensive foci of an area that is embedded within the neighbourhood and ties firmly into major features of the city. This research looks at node intersections that are typically places of break from continuous movements, occurring at crossings or convergence of paths. Kevin Lynch (1960) described these elements as junctions and functioning as nodes that make the city legible. The dynamic node is a junction point from which movement flows in and out where people make decisions for their desired direction. An appropriate urban node design is essential because people's attentions are heightened as they perceive nearby elements with more clarity than usual (Worrell, 2011). 


\section{RESEARCH METHODOLOGY}

The study employs an exploratory research methodology in eliciting data which consist of an observation and case study. The light penetration measurement and shadow casting analysis were carried out during the site visit to the study areas. Vegetation types were identified on the site and the planting arrangement was recorded for information on which tree canopy and planting arrangement provide the most shade at ground level by measuring the light intensity and visually examining the shadow casted. Photographic records were taken at different hours of the day to visually determine the degree of shade provision.

\subsection{OBSERVATION ON THE CASE STUDY LOCATION}

Site visit and investigation were conducted frequently within 4 weeks in two selected nodes intersections coded as Site A for the intersection of Jalan Raja Laut, Jalan Parlimen and Jalan Tun Perak; and Site B for the intersection of Jalan Pinang and Jalan $P$. Ramlee (Figure 2). Vegetation types and planting arrangements in Sites A and B were mapped out. Observation of human activities underneath the tree foliage were made to identify the appropriateness of the vegetation selection and planting arrangements of each site.

\subsection{LIGHT PENETRATION MEASUREMENT}

The research focused on the daylight intensity to measure the degree of light penetrating the tree foliage in the case study sites. The measurements were taken over a seven days period during different hours of the day in March representing the hottest month due to equinox. Daylight intensity data were recorded using the Lux-meter to measure sunlight illuminance in Klux. The measurement was taken at 3 areas within the site which were:

i. Under the tree foliage;

ii. 3 meters away from the tree foliage and; iii. At the centre of the hard surface exposed to sunlight.

\subsection{SHADOW CASTING STUDY}

In order to validate the daylight intensity data, the visual examination of the shadow casted was carried out. The shadow lengths were also measured from the tree trunk to the end of shadow line at three different times of the day (9.00a.m, 12.30p.m and 5.00p.m).

\subsection{STUDY LOCATIONS}

The study was carried out on two nodes at intersections in two commercial districts in the city centre of KL. KL is located in the Klang Valley between latitude $3^{\circ} 08^{\prime}$ North and longitude $101^{\circ} 44^{\prime}$ East. It has low variations of temperature throughout the year. KL has a hot-humid climate and experiences a wet tropical climate, in which the months of AprilMay and October-November can be considered as the wettest months, while December-March and June-September are the driest. During the day, the temperature ranges between $29-32$ ${ }^{\circ} \mathrm{C}$, while a temperature of about $22-24{ }^{\circ} \mathrm{C}$ is recorded at night (Elsayed, 2012b). Within the city of KL, many open areas are covered with blocks of marble, granite or tile. Although these materials store less heat than black tarmac, they still absorb large amounts of heat from direct sunlight and release the heat during late afternoons, evenings and early nights (Elsayed, 2006). Elsayed continues that traffic activities in the city centre of $\mathrm{KL}$ also contribute to high temperatures on the overall outdoor environment particularly on the street level. To reduce the heat temperature in the city and to transform KL into a world-class city by 2020, Dewan Bandaraya Kuala Lumpur (DBKL), the city hall, has targeted to increase the greenery in the city by planting 100,000 large-coverage trees.

Thus this paper is to study the effectiveness of those initiatives by investigating the selection of vegetation species and its planting arrangements at the main street intersections which act as nodes. 


\subsection{URBAN NODES SELECTION}

The two selected node intersections are i) Jalan Raja Laut, Jalan Parlimen and Jalan Tun Perak (referred to as Site A); and ii) Jalan Pinang and Jalan P. Ramlee (referred to as Site B). Both sites are illustrated in Figure 2. Both node intersections are located at primary streets in an urban commercial centre. The sites are constantly busy with motorized and nonmotorised transport movements during the days and nights. The areas are packed with high rise office buildings with few green spaces or shading trees. Site A is directly connected to Jalan Tuanku Abdul Rahman, which is one of the first street built in KL. Site $\mathrm{B}$ is located at the outskirts of Suria Kuala Lumpur City Centre (KLCC) mega development. The site is useful for connecting pedestrians walking at ground level in the Suria KLCC area to surrounding buildings. It is used as a rest space for people on foot with a considerable pedestrian volume.
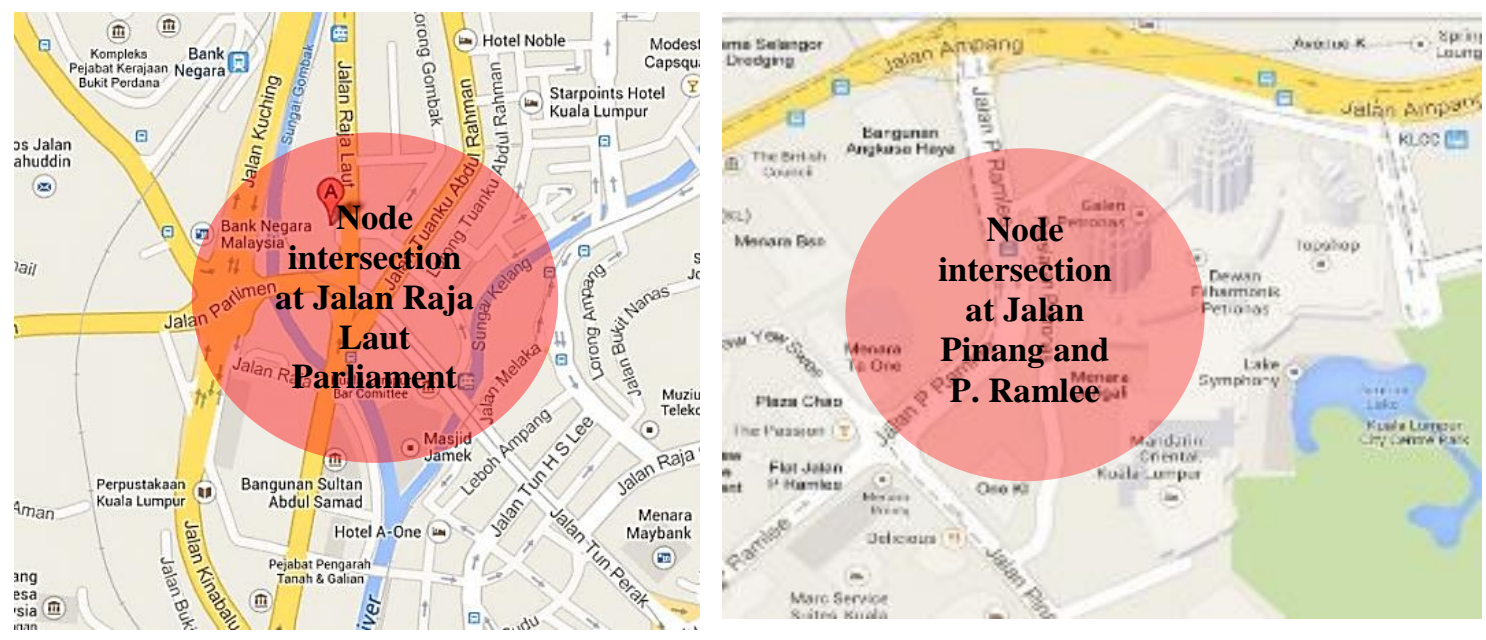

Figure 2: Nodes intersection Site A (left) and B (right) (Source: Google maps)

\subsection{RESEARCH ANALYSIS AND FINDINGS}

\subsection{DESIGN LAYOUT}

The findings identified two design arrangements namely the: i) clustered sparse arrangement at Site $\mathrm{A}$ and; ii) grid closeproximity arrangement at Site B (refer Figure 3). Site $\mathrm{A}$ was designed in a sparse arrangement with three different tree types namely Bucida molineti variegated, Livistona rotundifolia, and Peltophorum pterocarpum. There was approximately 3.5 meters distance between each tree. The trees were arranged in a formal planting arrangement with only part of the site covered by trees as can be seen in
Figure 3 (left). On Site B, only one type of tree was identified in the design of the space namely Hopea odorata. The tree is planted in a grid arrangement covering the entire site with a 1.5 meter distance between trees. The proximity of one tree to the next on both sites has allowed the canopies to overlap and provide greater resistance to visible and infrared radiation and casts a darker and longer shadow on the ground below thus providing more shade and reducing air temperature at the intersections. 


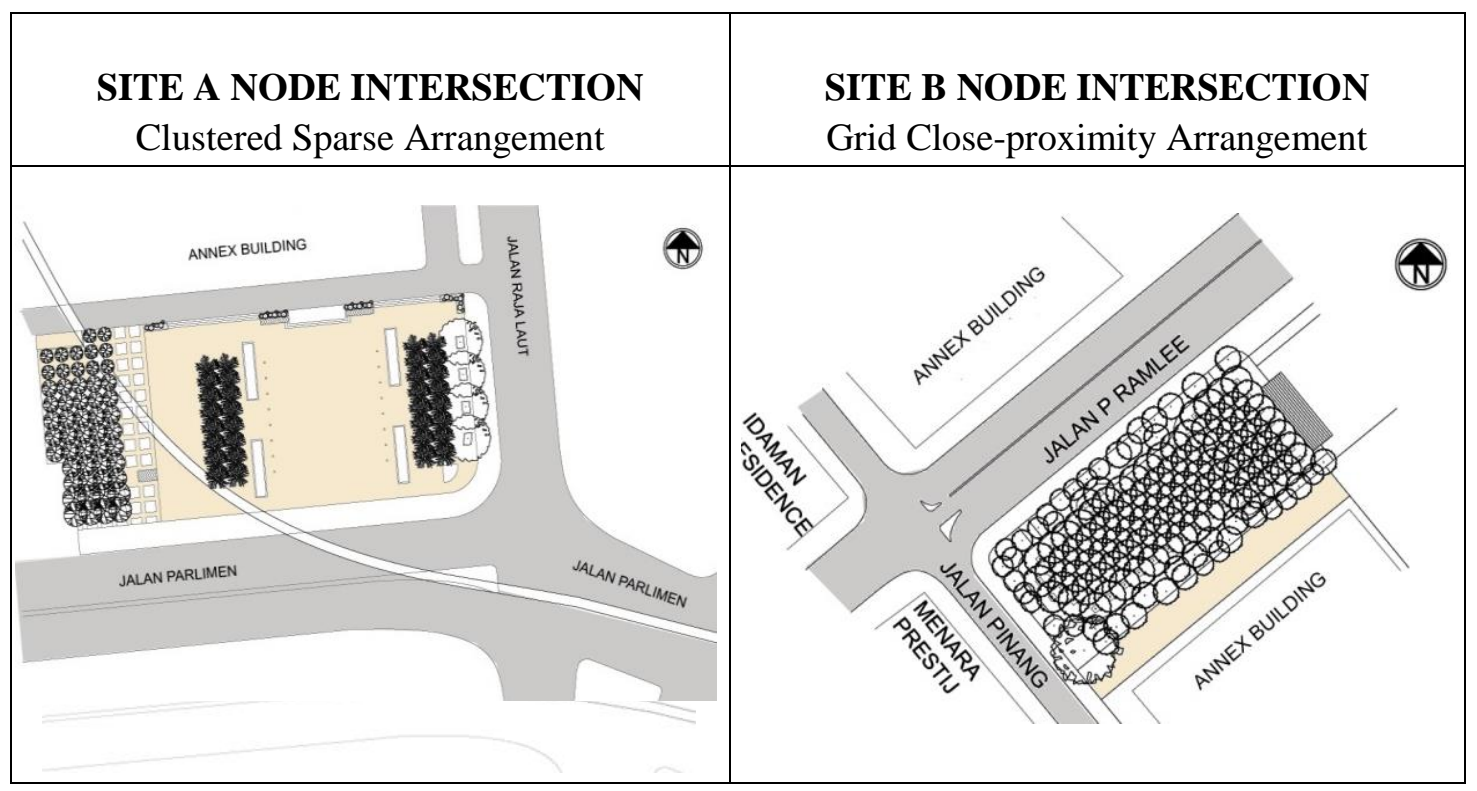

Figure 3: Layout of nodes intersection at Sites A (left) and B (right)

\subsection{VEGETATION IDENTIFICATION AND CHARACTERISTICS}

Livistona rotundifolia is a palm species with a single trunk with feather shape compound frond. The lower leaves in the tree structure thus allowing visual interaction for the pedestrians, which enhance visual safety. Bucida molineti variegated has its branches typically horizontal giving it a layered appearance, pointing skywards in symmetry. Finally, Peltophorum pterocarpum is a deciduous tree with oblong, spreading leaves. They were planted at the edge of the square along Site A characterized by its large canopy which casts a huge shade towards the square. The trees botanic descriptions on Site A are as below.

i. Bucida molineti variegated: branches pointing skywards in symmetry; twigs growing densely in storeys on whorls around the trunk. Leaves are tiny and variegated; more often used as an ornamental and shading plant; 12 meter mature height (refer to Table 1)

ii. Livistona rotundifolia: bold rounded evergreen leaves, this medium-sized, single-trunked fan-palm; mature height (12.2 - 22.9) meters; width (5.5m - 6.7) meters (refer to Table 1).

iii. Peltophorum pterocarpum: deciduous tree; mature height (15-25) meters; spread of (9-12) meters; irregular outline or silhouette crown; round; spreading; a vase shape crown; often used in landscaping (refer to Table 1).

On Site B, the Hopea odorata tree is characterised by its conical shape with simple and alternate leaf as discussed in Table 1. The tree botanic description on Site B is as below.

i. Hopea odorata: medium-sized to large evergreen tree; diameter up to 4.5 meters; leaves ovate-lanceolate, 7 14 by $3-7 \mathrm{~cm}$; large crown growing to 45 meters.

Hopea odorata trees in Site B are maintained regularly and shaped by pruning the lower branches. This has created a clear space beneath the trees making movement easy and also increasing visual safety. 
Table 1: Characteristics of the vegetation in Sites A and B nodes intersections.

\begin{tabular}{|c|c|c|c|c|}
\hline $\begin{array}{l}\text { Vegetation's } \\
\text { Characteristics }\end{array}$ & \multicolumn{3}{|c|}{ SITE A (JALAN RAJA LAUT) } & $\begin{array}{l}\text { SITE B (JALAN } \\
\text { PINANG) }\end{array}$ \\
\hline Sceintific Name & $\begin{array}{c}\text { Bucida } \\
\text { molineti } \\
\text { variegated }\end{array}$ & $\begin{array}{l}\text { Livistona } \\
\text { rotundifolia }\end{array}$ & $\begin{array}{l}\text { Peltophorum } \\
\text { pterocarpum }\end{array}$ & Hopea odorata \\
\hline Common Name & $\begin{array}{c}\text { Dwarf } \\
\text { Geometry } \\
\text { Tree }\end{array}$ & Footstool Palm & Yellow flame & $\begin{array}{c}\text { Pokok Merawan } \\
\text { Siput Jantan }\end{array}$ \\
\hline Images & & & & \\
\hline Type Of Plants & Erect Trees & Palms & Deciduous Tree & Deciduous Tree \\
\hline Mature Height (M) & 12 & 25 & 27 & 45 \\
\hline Leaf Shape & Alternate & Palmate & $\begin{array}{l}\text { Pinnate, pairs of } \\
\text { oblong leaflets }\end{array}$ & Simple and alternate \\
\hline Form/Shape/Colour & $\begin{array}{c}\text { Oval to } \\
\text { rounded } \\
\text { crown with } \\
\text { age }\end{array}$ & Spreading & Spreading & Conical \\
\hline Growth Character & Solitary & Solitary & Solitary & Solitary \\
\hline
\end{tabular}

\subsection{VEGETATION IDENTIFICATION AND HUMAN ACTIVITY}

The study also looked into the relationship between the tree types and human activities. Findings in Site A shows most of the pedestrians did not use the sidewalk underneath Livistona rotundifolia and Bucida molineti variegated as an interaction or activity space (refer Figure 4) instead they use the sheltered sidewalk under Peltophorum pterocarpum for pedestrian movement (7\% of total space). $65 \%$ of the total space area was covered by the hard surface which raised the ambient temperature during midday and through the evening. This created an uncomfortable environment which became less interactive indicated by the absence of pedestrians in the space throughout the day.

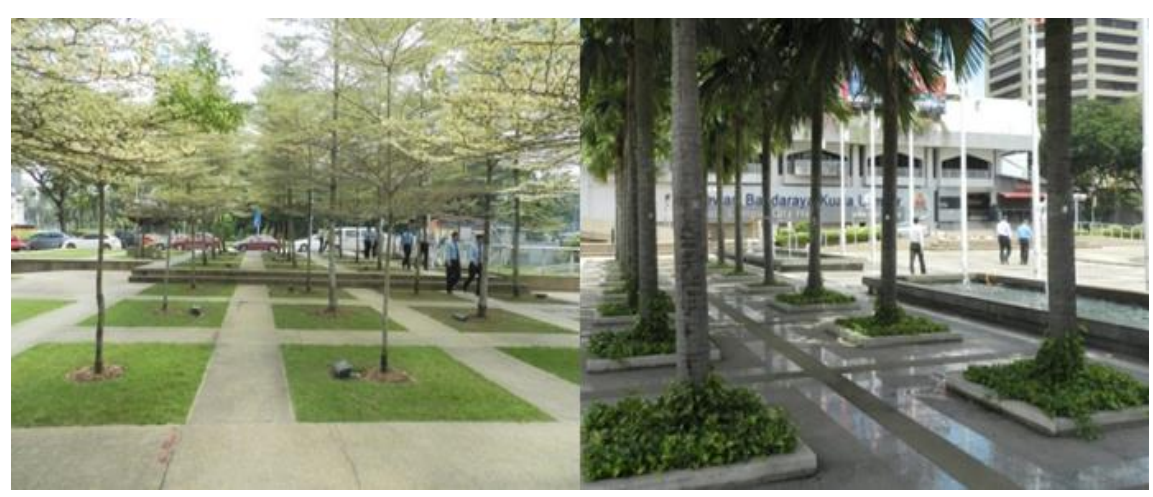

Figure 4: Formal clustered vegetation arrangement in grid layout in Site A

Contrary to the observation of Site A, the space in Site B is used for leisure such as relaxing, sitting, standing and taking naps because of its shadiness and breeziness. The observation showed pedestrians walking through the space and stopping for other activities such as sitting on benches within the space, or just stopping and standing for a few minutes to enjoy the place's ambience. This ambiance creates convenient and comfortable green space which formed a sense of enclosure that makes the public feel safe and secure as shown in Figure 5. 


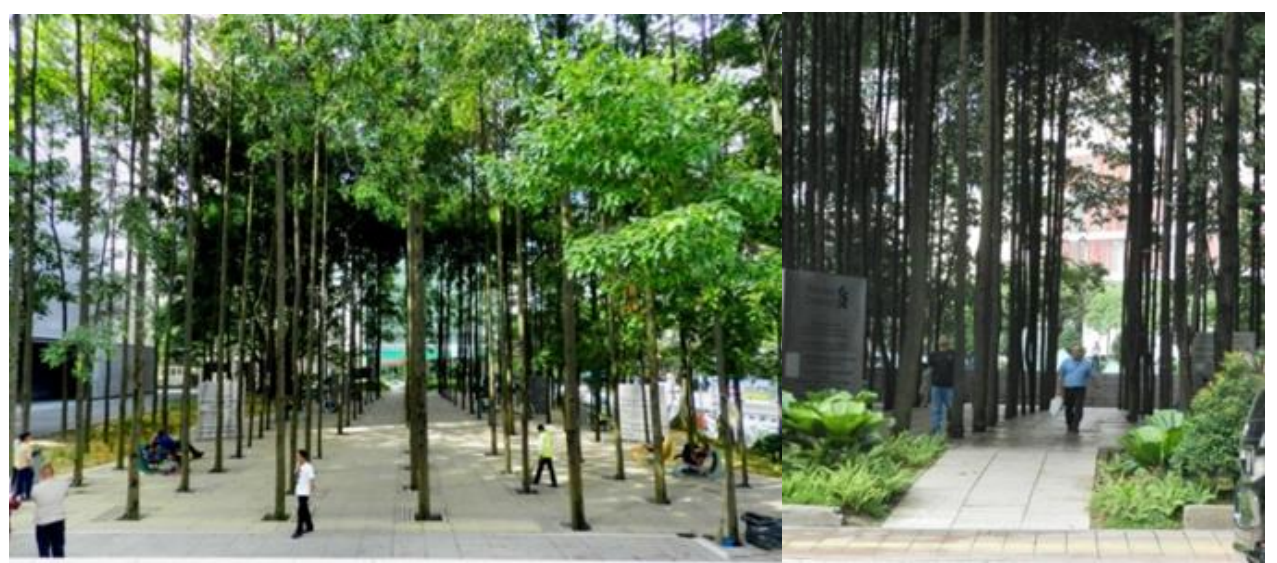

Figure 5: Single tree selection arranged in a grid and close planting arrangement Site B.

\subsection{LIGHT INTENSITY DATA}

On Site A, weekly light intensity data was taken at several positions including: i) under the vegetation; ii) 3 meters outside vegetation and at the centre of the hard surface with no shading; and iii) at four different times (11:30 a.m, 12:30 p.m, 1:30 p.m and 2:30 p.m) using the Lux meter. Three readings were taken at each point and the findings were averaged. The results of the intensity of visible light are shown in Figure 6. The line chart (Figure 6) shows a gradual increase in light intensity in the morning from 11.30 a.m till 12.30 p.m This is due to Kuala Lumpur experiencing of the overhead sun as its located near the equator $\left(3.1333^{\circ} \mathrm{N}, 101.6833^{\circ} \mathrm{E}\right)$ at noon. For this reason, the highest amount of visible and infrared radiation was received at 12:30 p.m
Beyond 12.30 p.m, the light intensity is seen to decrease gradually both outside and under the trees. The graph further shows that at $12: 30$ p.m, the centre of the square and 3 meters outside the vegetation shade, receive the highest amount of sunlight (78.22 Klux) due to the absence of a vegetative cover. The amount of visible light coming directly from the sun was reduced by more than half (53.44\%) under Bucida molineti variegated when compared to the uncovered area. It was further reduced by $61.74 \%$ under Livistona rotundifolia and further reduced by $89.14 \%$ under Peltophorum pterocarpum. This has shown that Peltophorum pterocarpum's trees foliage has filtered the highest amount of visible light thus expected to have the highest shading capacity.

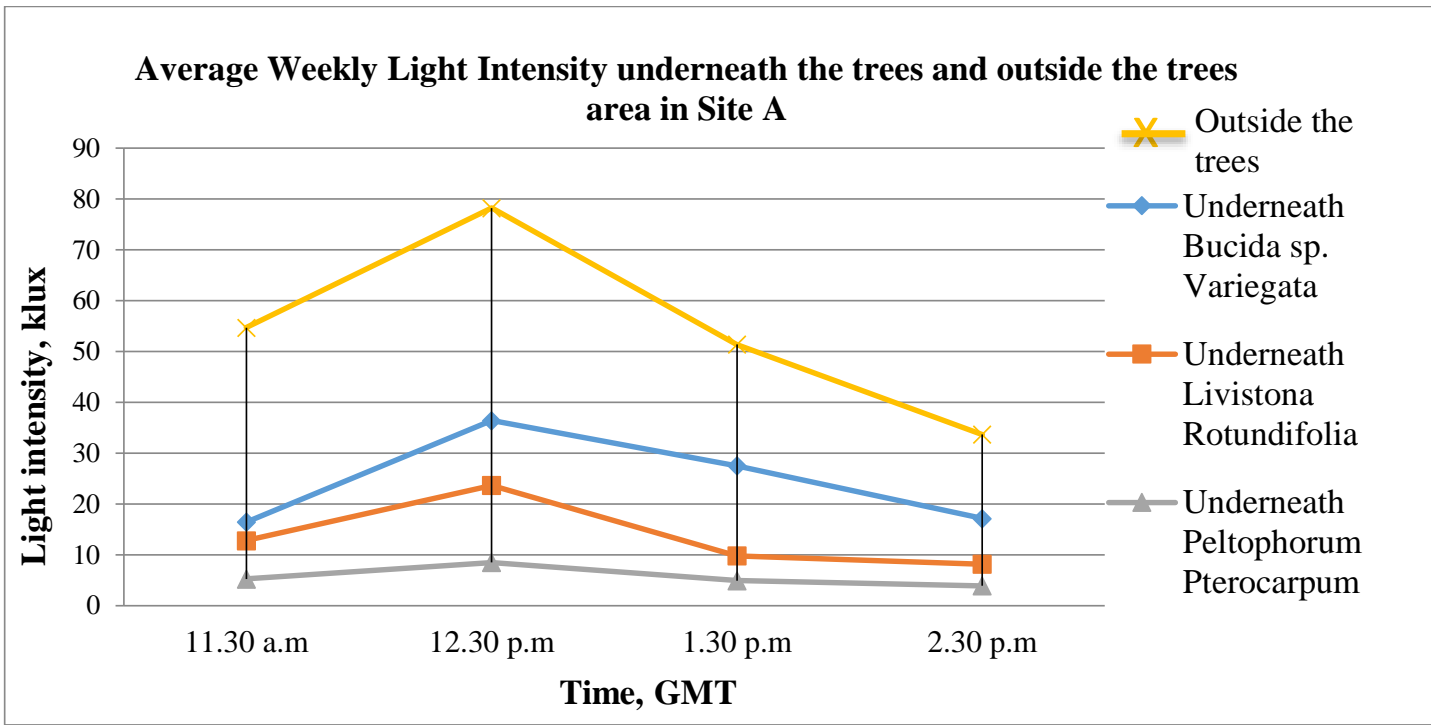

Figure 6: Average weekly light intensity underneath the vegetation and outside of the vegetation area in Site A. 
On Site B, weekly light intensity data were recorded. The measurement shows that the highest light intensity was received at 12:30 p.m the graph shows that at this hour, the centre of the space and 3 meters outside the vegetation areas received the highest amount of visible light (56.06 Klux). In comparison to Site A (78.22 Klux), the planting arrangement of the vegetation had a significant role in reducing the amount of light penetration on the ground surface. The dense planting arrangement covers approximately $90 \%$ of the total area on Site B. Only 1.5 Klux of visible light penetrated through the tree foliage. $98.23 \%$ of the visible light was reduced under Hopea odorata (refer to figure 7). This shows that a single vegetation selection of Hopea Odorata with dense and close arrangement has successfully filtered the highest amount of daylight and ultimately reducing terrestrial radiation and contributing to increased outdoor thermal comfort.

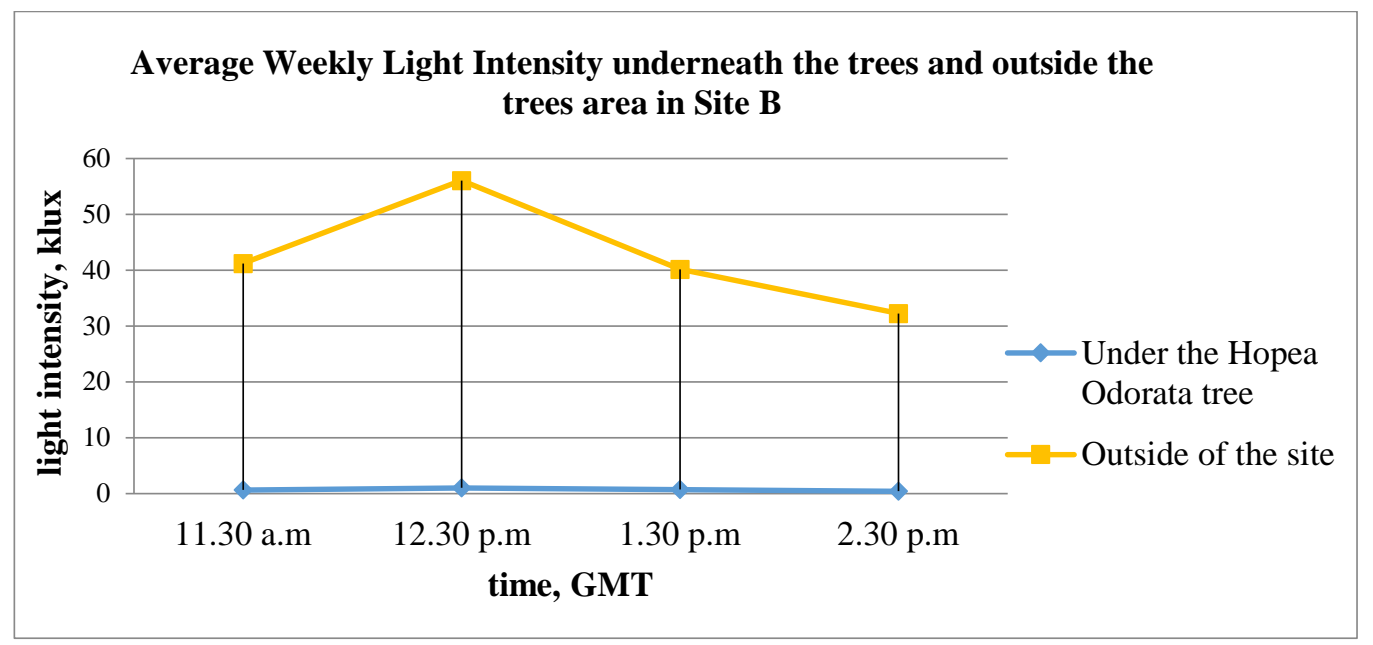

Figure 7: Average weekly light intensity underneath the trees and outside of the trees area in Site B node intersection.

\subsection{SHADOW CASTING STUDY}

The shadow casting study was conducted to validate the light intensity data. The shadow cast by each tree type is measured by the length of the shadow at different times of the day. The shadow is also visually examined with the aid of photographs. Measurements were recorded at three different times: 9.00 a.m, 12.30 p.m and 5.00 p.m Site A shows that deciduous species, Peltophorum pterocarpum provides the largest shadow coverage with its foliage, during the hottest hours around (12.30 p.m). This can be observed from the shadow lengths measured from the tree trunk to the highest point on the shadow cast (D1 $=4.8 \mathrm{~m}$ and D2 $=4.3 \mathrm{~m}$ ) as shown in Table 2. Livistona rotundifolia casts the second largest shadow coverage with its foliage with a shadow length of $\mathrm{D} 1=2.7 \mathrm{~m}$ and $\mathrm{D} 2=2.3 \mathrm{~m}$ during the hottest hours. Bucida molineti variegated cast the shortest shadow coverage with a shadow length of D1=2.2 $\mathrm{m}$ and D2=1.7 m. Bucida molineti variegated with its oval to rounded crown and alternate leaf shape allows much more sunlight to penetration its foliage as compare to Peltophorum pterocarpum that has spreading leaf form and random, unsymmetrical branch and leaf growth. Results show that the type of tree with similar foliage characteristic to Peltophorum pterocarpum can reduce the amount of daylight penetrating the leaf foliage of the space under.

Similar to Peltophorum pterocarpum in Site A, the Hopea odorata in Site B is also categorised as a deciduous tree. Although this species is shaped as conical with simple and alternate leaf, it could also filter large amounts of daylight mainly because of the grid and close proximity arrangement between trees. The denseness of the tree planting arrangement in Site B is successfully providing the shade under the tree from 9.00 a.m until 5.00 p.m as shown in the shadow casted image in Table 3. 
Table 2: Site A Shadow Casting Study.

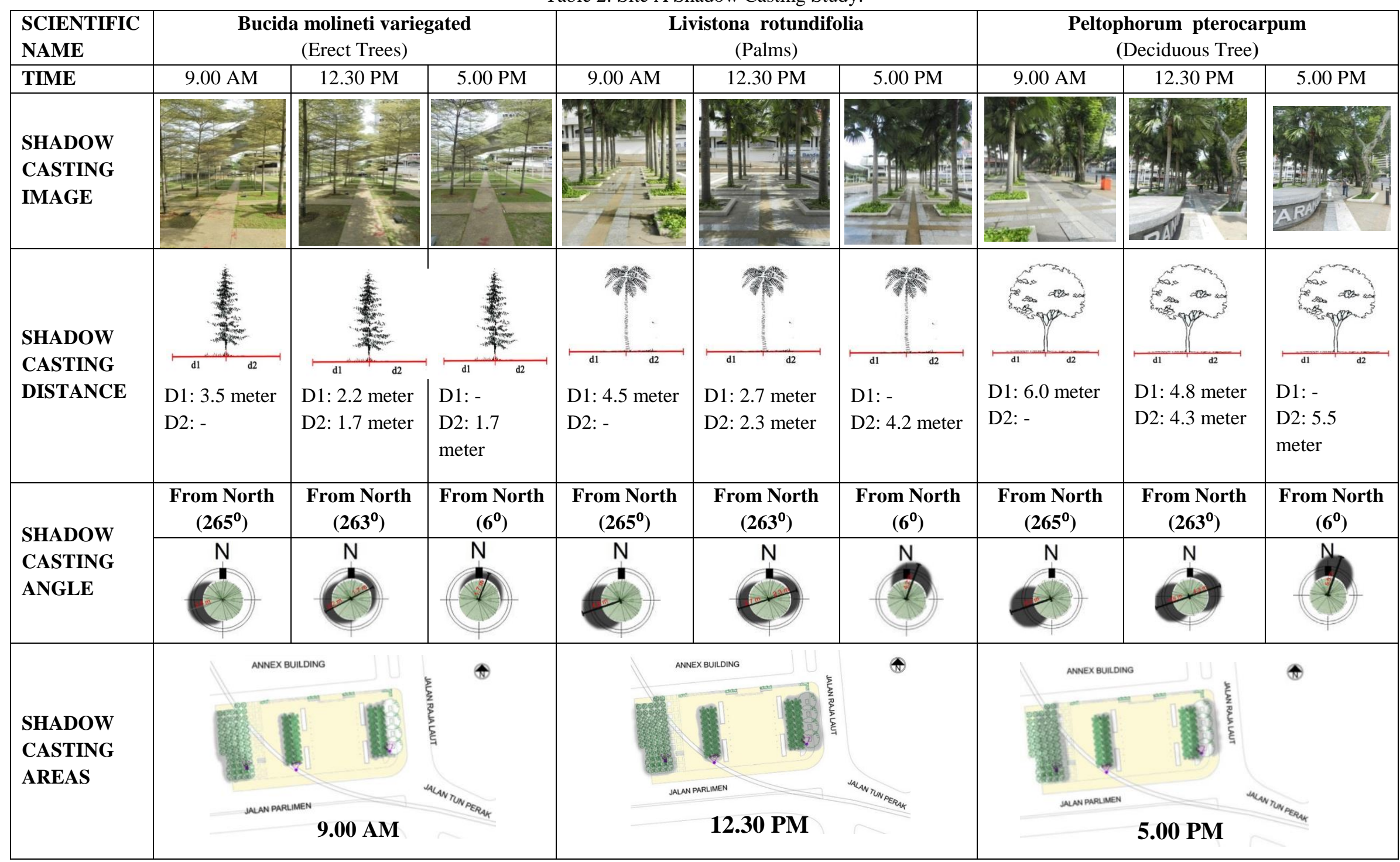


Table 3: Site B Shadow casting study at different times of the day

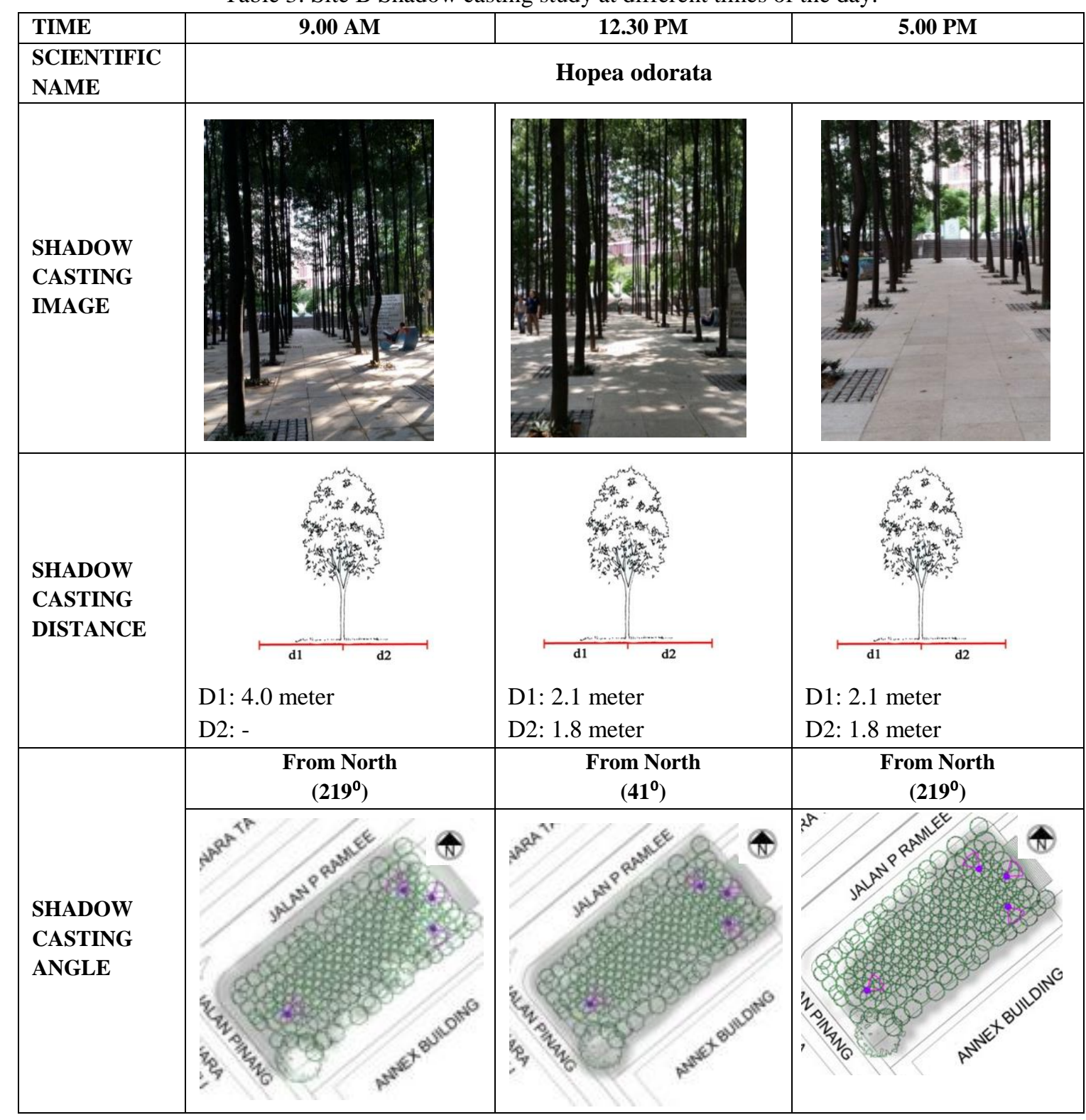




\section{DISCUSSIONS}

The data collected on different tree capacity to provide shade and planting arrangements in Site A and B revealed that selecting the appropriate vegetation type (with dense foliage) and the planting arrangement (proximity of one tree from the other) has significant influence on the amount of daylight penetrating the foliage to the space below and the shadow formed on the ground. The shade provided can further enhance the ambience of the area for pedestrians. The results show that trees can reduce around $47 \%$ to $99 \%$ of daylight penetration depending on the vegetation types and planting arrangement in congruence with Kenny et al., (2009a, b) and Brown (2011) theories.

Vegetation types planted at both study locations have given different percentages of light intensity values that explain the effectiveness of their characteristics and planting arrangement. Of the four vegetation types, trees with foliage characteristics similar to Peltophorum pterocarpum in Site A and Hopea odorata species in Site B provide greater shelter from visible light thereby casting more shadow over the site to the ground surface. The case studies investigated showed that Hopea odorata in Site B with conical shaped leaf arrangements and simple alternate leaf shape - expected to have less shading capacity - can become very effective when arranged appropriately as is done in Site $\mathrm{B}$ in a grid arrangement with small distances between trees. Furthermore, tree types like Peltophorum pterocarpum (though capable of significant reducing the amount of daylight flowing through as a single tree, as compared to Hopea odorata) can be less successful in reducing the amount of daylight penetrating the tree foliage in a sparse arrangement as can be observed on Site A

As mentioned earlier in section 3.5, the sites selected are at nodes intersections in proximity to major commercial areas and Primary Street that is used as a means to connect between places. The hot-humid climate and heat gain in Kuala Lumpur prevent many from walking. Nodes are an important element in such situations because they serve to break the prolonged pedestrian daily trips. They provide a space where they can rest and enjoy an aesthetically sheltered urban environment as protection from the hot sun. Providing more spaces that can sufficiently shelter and permit pedestrian activities can significantly boost commercial activities within the area as it acts as a means to attract more people to walk in urban public spaces (Gehl and Gemzoe, 2004; Lynch, 1960). Mapping out pedestrian routes and providing shading trees can alter the urbanscape to inject human activity back to the city streets as is observed in Site B where pedestrians have laid claim to the space. This is not the situation in Site A, even though the node intersection can serve a greater purpose due to its proximity to heritage and commercial sites in KL such as Jalan Tuanku Abdul Rahman, Masjid Jamek and Merdeka Square. Simple gestures such as the provision of vegetations in a proper planting arrangement for shading and thermal comfort of an outdoor environment can enhance the urban public spaces.

\section{CONCLUSION}

This paper set out to illustrate the effectiveness in shade creation of four vegetation types found on two different node intersections in providing shade and ultimately improving thermal comfort in hot-humid regions. This study has shown that some vegetations like Peltophorum pterocarpum in Site A and Hopea odorata in Site B have the ability to reduce light intensity and improve outdoor thermal comfort. For these vegetations to be more efficient, the physical character of the canopy, denseness of vegetation foliage, multiple layer arrangement of the leaves and the planting arrangement need to be taken into consideration during the design stage of the streetscape. Using Kenny et al. (2009a, b), Brown (2011) theories, it was assumed in the study that all vegetations will absorb a significant amount of visible infrared radiation depending on the degree of the shade provided. Furthermore, the degree of shading is 
dependent on the amount of daylight penetrating the foliage of the vegetations. Thus, the results imply that vegetation foliage characteristic is a critical factor that should be considered in respect to thermal comfort in selecting vegetation in urban spaces intended for human activity. Furthermore, appropriate planning with the planting arrangement and the tree type in the earlier stages of the design can help provide a thermally comfortable outdoor space for pedestrians. Increasing the number of vegetation in urban context could promote interactive open spaces with positive activities within the node intersections and attract more people to walk on city streets. The study is only at its initial stages and the preliminary part of the findings is presented due to time constraints. The extended study is underway and will consider both visible and infrared radiation measurements as is presented in previous literature investigating appropriate vegetation type for hot-humid climates. The research findings are most useful to designers to inform and help in understanding some of the necessary measures using appropriate vegetation types and planting arrangement, in designing urban nodes that are thermally comfortable for human activities in the urban environment.

\section{ACKNOWLEDGEMENTS}

This research was made possible with the sponsorship of University of Malaya Research Grand (UMRG) under the Sustainable Science Research Cluster (RP009-2012B Sustainable Urban Mobility for Livable City of Kuala Lumpur).

\section{REFERENCES}

Ahmed, K. S. (2003). Comfort in urban spaces: defining the boundaries of outdoor thermal comfort for the tropical urban environments. Energy and Buildings, 35(1), 103-110.

Akbari, H., Pomerantz, M., \& Taha, H. (2001). Cool surfaces and shade trees to reduce energy use and improve air quality in urban areas. Solar energy, 70(3), 295310 .
Brown, R. D. (2011). Ameliorating the effects of climate change: Modifying microclimates through design. Landscape and Urban Planning, 100(4), 372-374.

Elsayed I. S., 2006. "The effects of urbanization on the intensity of the urban heat island: a casestudy on the city of Kuala Lumpur", Dissertation, International Islamic University Malaysia.

Elsayed, I.S., (2009). Land Management and Its Effects on the Intensity of the Urban Heat Island: A Study on the City of Kuala Lumpur, Malaysia, Calgary, Canada, ACTA Press, track, pp: 650-033.

Elsayed I.S, (2012a). "Mitigation of the Urban Heat Island of the City of Kuala Lumpur, Malaysia”. Middle-East Journal of Scientific Research 11 (11): 1602-1613, 2012 ISSN 1990-9233 DOI: 10.5829/idosi.mejsr.2012.11.11.1590

Elsayed, I. S. (2012b). Type of Gardens that Reduce the Intensity of an Urban Heat Island. European Journal of Social Sciences, 35(3), 343-356.

Gehl, J., \& Lars. (2004). Public spaces-public life.

Hu, L., \& Brunsell, N. A. (2015). A new perspective to assess the urban heat island through remotely sensed atmospheric profiles. Remote Sensing of Environment, 158, 393-406.

Kenny, N. A., Warland, J. S., Brown, R. D., \& Gillespie, T. G. (2009a). Part A: Assessing the performance of the COMFA outdoor thermal comfort model on subjects performing physical activity. International journal of biometeorology,53(5), 415-428.

Kenny, N. A., Warland, J. S., Brown, R. D., \& Gillespie, T. G. (2009b). Part B: Revisions to the COMFA outdoor thermal comfort model for application to subjects performing physical activity. International journal of biometeorology,53(5), 429-441. 
Kleerekoper, L., van Esch, M., \& Salcedo, T. B. (2012). How to make a city climateproof, addressing the urban heat island effect. Resources, Conservation and Recycling, 64, 30-38.

Lindberg, F., \& Grimmond, C. S. B. (2011). The influence of vegetation and building morphology on shadow patterns and mean radiant temperatures in urban areas: model develoent and evaluation. Theoretical and applied climatology, 105(3-4), 311-323.

Lynch, K. (1960). The image of the city (Vol. 11). MIT press.

Mayer, H., Holst, J., Dostal, P., Imbery, F., \& Schindler, D. (2008). Human thermal comfort in summer within an urban street canyon in Central Europe. Meteorologische Zeitschrift, 17(3), 241250.

Meehl, Gerald A., and Claudia Tebaldi. "More intense, more frequent, and longer lasting heat waves in the $21 \mathrm{st}$ century." Science 305.5686 (2004): 994 997.

McPherson, E. G. (2001). Sacramento's parking lot shading ordinance: environmental and economic costs of compliance. Landscape and Urban Planning, 57(2), 105-123.

Myers, S. S., \& Patz, J. A. (2009). Emerging threats to human health from global environmental change. Annual Review of Environment and Resources,34, 223-252.

Patz, J. A., Campbell-Lendrum, D., Holloway, T., \& Foley, J. A. (2005). Impact of regional climate change on human health. Nature, 438(7066), 310-317.

Picot, X. (2004). Thermal comfort in urban spaces: impact of vegetation growth: case study: Piazza della Scienza, Milan, Italy. Energy and Buildings, 36(4), 329334.
Shahidan, M. F., Shariff, M. K., Jones, P., Salleh, E., \& Abdullah, A. M. (2010). A comparison of Mesua ferrea L. and Hura crepitans L. for shade creation and radiation modification in improving thermal comfort. Landscape and Urban Planning, 97(3), 168-181.

Shashua-Bar, L. and M.E. Hoffman, (2000). Vegetation as a Climatic Component in the Design of an Street: An Empirical Model for Predicting the Cooling 2: Effect of Urban Green Areas with Trees. Energy and Building, 31: 221-235.

Steven, M. D., Biscoe, P. V., Jaggard, K. W., \& Paruntu, J. (1986). Foliage cover and radiation interception. Field Crops Research, 13, 75-87.

Stocker, T. F., Qin, D., Plattner, G. K., Tignor, M., Allen, S. K., Boschung, J., \& Midgley, B. M. (2013). IPCC, 2013: climate change 2013: the physical science basis. Contribution of working group I to the fifth assessment report of the intergovernmental panel on climate change.

Streiling, S., \& Matzarakis, A. (2003). Influence of single and small clusters of trees on the bioclimate of a city: a case study. Journal of Arboriculture,29(6), 309-316.

Thorsson, S., Lindberg, F., Björklund, J., Holmer, B., \& Rayner, D. (2011). Potential changes in outdoor thermal comfort conditions in Gothenburg, Sweden due to climate change: the influence of urban geometry. International Journal of Climatology, 31(2), 324-335.

Worrell,V.(2011) Inhabiting the Transitional A Transit Hub for Ottawa's Bayview Yards, A thesis Master of Architecture (M.Arch Professional), Azrieli School of Architecture and Urbanism, Carleton University, Ottawa, Canada 2011. 